\title{
Psychotherapy
}

\section{Ambivalence and Innovative Moments in Grief Psychotherapy: The Cases of Emily and Rose}

Daniela Alves, Pablo Fernández-Navarro, António P. Ribeiro, Eugénia Ribeiro, and Miguel M. Gonçalves

Online First Publication, February 11, 2013. doi: 10.1037/a0031151

CITATION

Alves, D., Fernández-Navarro, P., Ribeiro, A. P., Ribeiro, E., \& Gonçalves, M. M. (2013, February 11). Ambivalence and Innovative Moments in Grief Psychotherapy: The Cases of Emily and Rose. Psychotherapy. Advance online publication. doi: 10.1037/a0031151 


\title{
Ambivalence and Innovative Moments in Grief Psychotherapy: The Cases of Emily and Rose
}

\author{
Daniela Alves, Pablo Fernández-Navarro, António P. Ribeiro, Eugénia Ribeiro, and Miguel M. Gonçalves \\ University of Minho
}

\begin{abstract}
Several studies have suggested that the process of narrative change in psychotherapy occurs through the emergence and expansion of moments of novelty, known as innovative moments (IMs), that allow changes in the problematic self-narrative responsible for the client's suffering. However, as these IMs challenge typical (and problematic) ways of acting, feeling, and thinking, they may also generate discrepancy or uncertainty. Clients may reduce uncertainty by returning to the problematic self-narrative immediately after the emergence of an IM, thus ensuring the homeostasis of the previous meaning system. This cyclical movement is a form of ambivalence, which can maintain problematic stability across therapy and lead to therapeutic failure. In this study, we identified return to the problem markers (RPMs), which are empirical indicators of the ambivalence process, for all IMs in two cases of constructivist grief psychotherapy. Both cases evidenced a high percentage of IMs with RPMs, and the evolution of IMs and RPMs along treatment was significantly correlated. We suggest that stability of the ambivalence process in grief psychotherapy may represent a form of self-protection from the anxiety or guilt of releasing pain as a disconnection from the deceased.
\end{abstract}

Keywords: innovative moments, ambivalence, constructivist grief psychotherapy

Recent research on bereavement has demonstrated that the incapability to make sense of and integrate loss into a new personal narrative is associated with complicated protracted grief symptomatology (Coleman \& Neimeyer, 2010; Currier, Holland, Coleman, \& Neimeyer, 2007; Keesee, Currier, \& Neimeyer, 2008; Lichtenthal, Currier, Neimeyer, \& Keesee, 2010). Here, we present a proposed narrative framework of analysis that gives special relevance to the study of the narrative processes involved in selfreconstruction in constructivist grief psychotherapy.

\section{Narrative Framework: Psychotherapy as Meaning Reconstruction}

As poetically stated by Bruner (2002), "a self is most likely the most impressive work of art we ever produce" (p.14). According to the narrative framework, humans shape their existence as active storytellers, recounting their experiences and personal stories to others, and being influenced by the contributions of others to this dialogue (Bruner, 1990; McAdams, 1993; Sarbin, 1986). These stories "not only govern which meanings are attributed to events, but also select which events are included and which are left out of the story" (Polkinghorne, 2004, p. 58). As these specific interpretations can narrow people's understanding of themselves and the world around them, some self-narratives may become dysfunctional and inflexible (Dimaggio, 2006; Hermans \& Kempen,

Daniela Alves, Pablo Fernández-Navarro, António P. Ribeiro, Eugénia Ribeiro, and Miguel M. Gonçalves, School of Psychology, University of Minho, Braga, Portugal.

Correspondence concerning this article should be addressed to Miguel M. Gonçalves, School of Psychology, University of Minho, 4710-057 Braga, Portugal. E-mail: mgoncalves@psi.uminho.pt
1993). As suggested by White and Epston (1990), maintenance of these dominant narratives may confine all experiences into a problematic self-narrative, which becomes biased toward the negative details of the experience (Gonçalves \& Machado, 1999). If we consider the experience of losing a significant person, narrative dominance may occur when the survivor's life becomes regulated by the "narrative of loss," privileging the most painful and threatening details of a changed reality (Currier \& Neimeyer, 2006).

\section{Narrative Reconstruction: Innovative Moments and Protonarratives}

Several studies of psychotherapy have shown that the processes of narrative transformation occur through the emergence and expansion of alternative details of the problematic self-narrative, known as innovative moments (IMs) (Alves, Mendes, Gonçalves, Neimeyer, 2012; Gonçalves, Mendes, Ribeiro, Angus, \& Greenberg, 2010; Matos, Santos, Gonçalves, \& Martins, 2009; Mendes et al., 2010; Ribeiro \& Gonçalves, 2011; Santos, Gonçalves, Matos, \& Salvatore, 2009; Santos, Gonçalves, \& Matos, 2010). Inspired by White and Epston's (1990) notion of "unique outcomes," IMs are experiences that are not predicted by the problematic self-narrative (Gonçalves, Matos, \& Santos, 2009). The Innovative Moments Coding System (IMCS; Gonçalves, Ribeiro, Matos, Santos, \& Mendes, 2010; Gonçalves, Ribeiro, Mendes, Matos, \& Santos, 2011) defines five types of IMs (action, reflection, protest, reconceptualization, and performing change) that are exhibited by clients during therapeutic conversation. Examples of these IMs are presented in Table 1. One of the main results of studies using IMCS is that poor-outcome (PO) and good-outcome (GO) cases have different IM profiles. Initially, IMs appear in both PO and GO cases, although in GO cases, their duration and diversity are higher and they tend to increase throughout the treatment. Addi- 
Table 1

The Innovative Moments Coding System (Gonçalves, Ribeiro, Matos, et al., 2010)

\begin{tabular}{|c|c|c|}
\hline Types of IM & Subtypes & Contents \\
\hline Action IM (A) & & New coping behaviors facing anticipated or existent obstacles \\
\hline \multirow{4}{*}{$\begin{array}{l}\text { Actions or specific behaviors against the } \\
\text { problem(s) }\end{array}$} & & Effective resolution of unsolved problem(s) \\
\hline & & Active exploration of solutions \\
\hline & & Restoring autonomy and self-control \\
\hline & & Searching for information about the problem(s) \\
\hline Reflection IM (R) & $\begin{array}{l}\text { i) Creating distance from the } \\
\text { problem(s) }\end{array}$ & $\begin{array}{l}\text { Comprehension-reconsidering problem(s)' causes and/or } \\
\text { awareness of its effects }\end{array}$ \\
\hline \multirow{6}{*}{$\begin{array}{l}\text { Thinking processes that indicate the } \\
\text { understanding of something new that } \\
\text { makes the problem(s) illegitimate (e.g., } \\
\text { thoughts, intentions, interrogations, } \\
\text { doubts) }\end{array}$} & & New problem(s) formulation \\
\hline & & Adaptive self-instructions and thoughts \\
\hline & & $\begin{array}{l}\text { Intention to fight problem(s)' demands, references of self-worth, } \\
\text { and/or feelings of well-being }\end{array}$ \\
\hline & ii) Centered on change & Therapeutic process - reflecting about the therapeutic process \\
\hline & & $\begin{array}{l}\text { Change process - considering the process and strategies } \\
\text { implemented to overcome the problem(s); references of self- } \\
\text { worth and/or feelings of well-being (as consequences of change) }\end{array}$ \\
\hline & & $\begin{array}{l}\text { New positions-references to new/emergent identity versions in the } \\
\text { face of the problem(s) }\end{array}$ \\
\hline Protest IM (P) & i) Criticizing the problem(s) & $\begin{array}{l}\text { Position of critique in relation to the problem(s) and/or others who support } \\
\text { it. The other could be an internalized other or facet of oneself }\end{array}$ \\
\hline \multirow{2}{*}{$\begin{array}{l}\text { Moments of critique that involve some } \\
\text { type of confrontation (directed at } \\
\text { others or versions of oneself); could be } \\
\text { planned or actual behaviors, thoughts, } \\
\text { or/and feelings }\end{array}$} & ii) Emergence of new positions & Positions of assertiveness and empowerment \\
\hline & & Repositioning oneself toward the problem(s) \\
\hline Reconceptualization IM (RC) & & RC always involves two dimensions: \\
\hline \multirow{4}{*}{$\begin{array}{l}\text { Process description at a meta-cognitive } \\
\text { level (the client not only manifests } \\
\text { thoughts and behaviors out of the } \\
\text { problem(s) dominated story but also } \\
\text { understands the processes that are } \\
\text { involved). If the RC includes } \\
\text { Performing Change (PC), we should } \\
\text { code RC with PC (RCPC) }{ }^{\mathrm{a}}\end{array}$} & & $\begin{array}{l}\text { A. Description of the shift between two positions (past and } \\
\text { present) and }\end{array}$ \\
\hline & & B. The process underlying this transformation \\
\hline & & \\
\hline & & \\
\hline Performing Change IM (PC) & & $\begin{array}{l}\text { Generalization into the future and other life dimensions of good } \\
\text { outcomes }\end{array}$ \\
\hline \multirow{5}{*}{$\begin{array}{l}\text { References to new aims, experiences, } \\
\text { activities, or projects, anticipated or in } \\
\text { action, as consequence of change }\end{array}$} & & Problematic experience as a resource to new situations \\
\hline & & Investment in new projects as a result of the process of change \\
\hline & & $\begin{array}{l}\text { Investment in new relationships as a result of the process of } \\
\text { change }\end{array}$ \\
\hline & & Performance of change: new skills \\
\hline & & Re-emergence of neglected or forgotten self-versions \\
\hline
\end{tabular}

tionally, in GO cases, action, reflection, and protest IMs tend to progress to reconceptualization and performing change in the middle and later parts of treatment, an uncommon movement in PO cases (Gonçalves et al., 2012; Matos et al., 2009; Mendes et al., 2010). Furthermore, as reconceptualization and performing change emerge, new action, reflection, and protest IMs develop, allowing for the development of new sequences of reconceptualization and performing change IMs that consolidate the narrative change of the self (Gonçalves, Matos, Santos, 2009).

Different from the narrative flexibility proposed by the elaboration of IMs, problematic self-narratives promote the maintenance of implicit rules that shape the meaning system of clients, influencing their behavior, thoughts, feelings, and relationships. As an example, in a prolonged grief case, the client may shape his or her life by the rule "I stopped living my life, it no longer makes sense because he or she is no longer here." This implicit rule has a wide influence on the client's existence, creating strong restraints on his or her life. From this perspective, IMs can be conceived as exceptions to the rule, as they introduce novelty into a client's life, challenging the problematic self-narrative. For example, in a successful grief case of a mother who lost her unborn child, Alves and collaborators (2012) found that the emergence and expansion of IMs were associated with a gradual transformation of the problematic self-narrative (characterized by confusion, anger, and disbelief) into a more healthful story of loss.

Another important feature of IM development is that they tend to cluster around different themes. For instance, in the aforementioned example, there may be two different alternative, or innovative, themes: "Life goes on and nothing will bring back my lost 
one" and "I may try to find a new purpose to live, I don't need to give up without even trying." Moreover, different types of IMs, from action to performing change, may be present in each of these themes. We termed these alternative themes protonarratives, as they represent potential new, more adjusted, self-narratives. In summary, in the course of the treatment, IMs with several different meanings start to become organized into provisory themes, or protonarratives, which differ from the themes embedded in the problematic self-narrative (Ribeiro et al., 2011). Different protonarratives emerge along treatment, progressing into a new selfnarrative throughout successful therapy.

\section{Maintaining Problematic Self-Narratives: The Role of Ambivalence}

IMs can be understood as unfamiliar experiences that challenge a client's problematic, but usual, way of experiencing the world. This unfamiliarity of the experiences involved in IMs could thus generate uncertainty or ambivalence (Gonçalves \& Ribeiro, 2012; Ribeiro \& Gonçalves, 2010). As suggested by Hermans and Dimaggio, even though uncertainty "challenges our potential for innovation and creativity," it also "entails the risks of a defensive and monological closure of the self" (Hermans and Dimaggio, 2007, p.10). Recent studies using the IMCS have shown that in both PO cases (Santos et al., 2010) and in the initial and middle phases of GO cases (Ribeiro \& Gonçalves, 2011), clients tend to attenuate the impact of IMs by returning to the problematic self-narrative. Gonçalves, Ribeiro, Stiles, et al. (2011) proposed that the identification of these "return to the problem markers" (RPMs) could be an empirical access to the phenomenon of ambivalence in psychotherapy. These are instances in which an IM is attenuated by a return to the problematic self-narrative. The following is an example of this process: "I don't want to suffer anymore (reflection IM) but I don't know how to do it" (RPM). In this process, the client oscillates between the production of an IM, which liberates him or her from the oppression of problematic self-narratives, but as the innovation menaces his or her sense of self-stability, he or she quickly makes a return to the problematic self-narrative.

According to Gonçalves and collaborators (e.g., Ribeiro \& Gonçalves, 2010; Gonçalves, Ribeiro, Stiles, et al., 2011), the systematic recurrence of RPMs throughout the therapeutic process can inhibit the development or transformation of the self-narrative, fostering therapeutic failure. These claims were supported by one study of narrative therapy (Gonçalves, Ribeiro, Stiles, et al., 2011), where it was found that RPMs occurred with significantly greater frequency in PO cases compared with GO cases.

To the best of our knowledge, there is no research to date on the emergence of RPMs in the process of narrative change in grief psychotherapy. Studying this process might be particularly important because, as stated by Neimeyer (2006b), major losses can menace a person's efforts at self-coherence, stimulating an active redefinition of the previous self-narrative.

\section{Grief Psychotherapy: The Meaning Reconstruction Activity}

Although the majority of persons respond resiliently to loss (Bonanno, 2004), there is evidence that approximately $10 \%$ to $20 \%$ of the bereaved manifest serious difficulties in making sense of this experience (Bonnano, Wortman, \& Nesse, 2004), and develop a complicated grief response (Prigerson et al., 1995; Prigerson \& Maciejewski, 2006) or prolonged grief disorder (Boelen \& Prigerson, 2007; Prigerson et al., 2009). Considering the incapacity to integrate loss as a significant predictor of grief severity, several authors have been suggesting the relevance of meaning-making strategies with grieving individuals (Keesee et al., 2008; Lichtenthal et al., 2010; Neimeyer, Burke, Mackay, \& van Dyke-Stringer, 2010). One recent randomized controlled trial showed, for example, the effectiveness of meaning-making forms of journaling on prolonged grief and distress symptomatology (Lichtenthal \& Cruess, 2010).

Along with the relevance of these meaning-centered interventions, this study explores how two constructivist grief clients transform-through the elaboration of IMs-or maintainthrough the recurrence of RPMs - their problematic selfnarratives. Finally, we reflect on the implications of these processes on narrative change, exploring the themes, or protonarratives, through which this change occurred.

This research aimed to add relevant information to the existing knowledge of meaning-making processes in grief therapy by (a) analyzing two complicated grief cases previously unexamined, and (b) examining the relationship between IMs and RPMs with the processes of loss integration and search for well-being after loss, which have not been analyzed previously.

\section{Method}

\section{Clients}

Emily. Emily (pseudonym) is a 30-year-old Portuguese White female, babysitter and housemaid, who gave permission for her materials to be used for research. She attended 13 therapeutic sessions 2 years after the death of her 80-year-old grandmother who died after a stroke. She lived with her 3-year-old daughter in the same town as her close family; her husband was an emigrant worker in Switzerland. She described her physical proximity to her family and her role as a family caregiver as central features of her personality. Emily's problematic self-narrative pointed to a mixture of emotions ruled by pain and guilt, mostly for not having been able to give a goodbye kiss to her grandmother on the day of her funeral, imagining her grandmother as being sad and disappointed. In the initial phases of the process, Emily sustained a persistent centrality on physical contact and proximity with her loved ones as central aspects of the connection with her family, showing difficulty investing in the creation of a more representational and symbolic relationship with her grandmother. She had also difficulty in making sense of the concept of death as a persistent physical separation, feeling completely devastated by the idea of losing another significant person. In general, she described herself as a depressed person who was unable to return to her previous work and social functioning, and felt isolated at home.

Rose. Rose (pseudonym) is a 58-year-old Portuguese woman who worked as a child educator and was retired at the time of therapy. She took part in therapy 3 years after the death of her 17-year-old son, from prostate cancer, and 6 months after the death of her husband, ran over by a car at his place of work. She lived in a small city with her 23-year-old daughter, located far from 
other family members. Rose's problematic self-narrative was ruled by an intense feeling that her life no longer made sense. When she started therapy, she described the "wish of having her son and husband in her life in a different way" as her main therapeutic goal. Before therapy, she was already involved in the search for a symbolic and less painful connection with them through the reading of grief books and attendance at a self-help group for bereaved parents. However, these attempts did not have the results she expected ("being more comforted") and she felt that her life was empty and meaningless. Along with these feelings, she reported intense guilt related to several choices she made in the past (e.g., to search for and provide cancer treatments to her son only in Portugal or insisting that her husband kept working at the place where he ended up dying). Thus, she felt that she did not deserve the right to go out and enjoy herself because her son and husband were deprived of that right. This problematic self-narrative ended up impairing her personal and social functioning, resulting in her being isolated at home. Additionally, she reported intense discomfort dealing with family meetings, feeling that the core part of her family had been taken from her.

\section{Therapist and Therapy}

Both clients attended psychotherapy at a Portuguese university clinic, where they were seen weekly in individual therapy sessions. They were treated by the same female therapist, a 25 -year-old clinical psychology doctoral student with 3 years of clinical experience as psychotherapist and 2 years of experience in constructivist grief psychotherapy. A skilled therapist with 18 years of clinical experience as a constructivist psychotherapist supervised the clinical practice to ensure adherence to the constructivist therapeutic model. Video and audio recordings were made of all sessions in both cases.

The therapy was developed from the constructivist meaning reconstruction approach proposed by Neimeyer $(2001,2006 a)$ and involved an initial exploration of the client's story of loss, oriented by the "Meaning Reconstruction Interview" (Neimeyer, 2006a, pp. 166-169). This first contact, guided by an empathic validation and exploration of the most painful aspects of the grieving experience, allowed for the identification of the multiple challenges and resources of each client. Although this constructivist approach does not have a specific or manualized structure, it has the central objective of helping clients to find a new understanding and healthful significance of their losses by coconstruction of new meanings that potentiate self-development (Neimeyer et al., 2010).

In Emily's case, the main therapeutic activities were "narrative retelling" (Neimeyer et al., 2010, p.76) and "imaginal conversations" (Shear, Boelen, \& Neimeyer, 2011, p. 149) with the deceased. By proposing Emily's involvement in these meaningoriented activities, the therapist (grounded in constructivist grief therapy) actively invested in the coconstruction of new and less anguished elaborations of the most painful episodes of her grief (Neimeyer et al., 2010), being consistent with the assumptions postulated by the constructivist grief therapy (Neimeyer, 2006a). These therapeutic activities were also organized to stimulate the construction of a more symbolic postmortem connection (Field, 2006; Shear et al., 2011) associated with less grief distress (Field, Nichols, Holen, \& Horowitz, 1999).
In Rose's case, "imaginal conversations" (Shear et al., 2011, p. 149) and "therapeutic writing" (Neimeyer et al., 2010, p.78) were the main activities. Being also consistent with the meaning-making approach proposed by the constructivist grief therapeutic model (Neimeyer, 2006a), the therapist created an opening space for discussion and dialogue to allow the client to elaborate on a more compassionate viewpoint of her lost loved ones, thus promoting a new perspective around the most anguishing episodes of her experience of loss (Neimeyer et al., 2010).

This study is part of a process research study approved by the ethical committee of the local hospital (the institution that referred cases for treatment), in which clients were offered 15 sessions of therapy over 22 weeks. Emily completed 13 sessions, at which time the therapeutic aims were achieved and no more therapy was required. Rose was referred for further treatment, given the continued presence of complicated grief symptomatology at the end of the clinical trial.

\section{Researchers}

The first and second authors conducted the IMs, the RPM, and protonarrative analysis of all the sessions of both cases. Both authors were doctoral students in clinical psychology. The third author, also a doctoral student in clinical psychology, served as an auditor of the RPM and protonarrative coding, as he was experienced with these procedures. Finally, the fourth and fifth authors, both university faculty members in clinical psychology and skilled researchers and psychotherapists, contributed to the organization and elaboration of this study.

\section{Measures}

Outcome measures.

Structured Clinical Interviews for the Diagnostic and Statistical Manual of Mental Disorders, fourth edition, text revision (DSM-IV-TR; American Psychological Association, 2000) Axis I and Axis II. Structured Clinical Interviews for DSM-IV-TR Axis I (SCID-I; First, Spitzer, Gibbons, \& Williams, 2002) and Axis II (SCID-II; First, Gibbon, Spitzer, Williams, \& Benjamin, 1997) are structured clinical interviews grounded on the DSM$I V-T R$ diagnostic criteria that allow for the assessment of a client's disorders on Axis I (mood, psychotic, and anxiety disorders) and Axis II (personality disorders). Inter-rater reliability ranged from 0.83 to 0.85 in SCID-I (Del-Ben et al., 2001) and was 0.63 in SCID-II (Weertman, Arntz, Dreessen, Velzen, \& Vertommen, 2003).

Inventory of Complicated Grief. The Inventory of Complicated Grief (ICG; Prigerson et al., 1995) is a 19-item questionnaire that assesses the severity of grief symptoms in the previous month. The items are rated on a 5-point Likert scale, from 0 to 4 , with total possible scores ranging from 0 to 76 . A total score of $>25$ suggests complicated grief. The scale shows good internal consistency (0.94; Prigerson et al., 1995). We used the Portuguese adaptation by Frade, Pacheco, Sousa, and Rocha (2009), which also presents good internal consistency (0.91; Frade et al., 2009). The cutoff score for the Portuguese population was 30 (Sousa \& Rocha, 2011).

Beck Depression Inventory-II. The Beck Depression Inventory-II (BDI-II; Beck, Steer, \& Brown, 1996) is a 21-item 
questionnaire that assesses depressive symptoms. The items are rated on a 4-point Likert scale, from 0 to 3, with total scores ranging from 0 to 63 . The scale shows high internal consistency (0.91; Steer, Brown, Beck, \& Sanderson, 2001). In this study we used the Portuguese adaptation by Coelho, Martins, and Barros (2002), with a cutoff of 14.29 and a Reliable Change Index (RCI, Jacobson \& Truax, 1991) of 8.46, as proposed by Seggar, Lambert, and Hansen (2002).

Outcome Questionnaire. The Outcome Questionnaire (OQ45.2; Lambert et al., 1996) is a 45-item questionnaire that assesses a client's clinical progress throughout the therapeutic process. It evaluates the client's progress in three dimensions: subjective discomfort, interpersonal relationships, and social role functioning. The items are rated on a 5-point Likert scale, from 0 to 4 , with total scores ranging from 0 to 180 . This questionnaire has good testretest reliability (0.84) and high internal consistency (0.93; Lambert et al., 1996). We used the Portuguese version by Machado and Klein (2006) that has good internal consistency (Machado \& Fassnacht, 2012). The RCI (Jacobson \& Truax, 1991) is 18 points and the cutoff score is 62 .

\section{Process measures.}

Innovative Moments Coding System. The IMCS (Gonçalves, Ribeiro, Matos, et al., 2010; Gonçalves, Ribeiro, Mendes, et al., 2011) is a system of qualitative analysis that identifies five categories of IMs: action, reflection, protest, reconceptualization, and performing change (see each IM description in Table 1). Previous studies using the IMCS (Gonçalves et al., 2012; Matos et al., 2009; Mendes et al., 2010) reported reliable agreement between judges in coding, with Cohen $\kappa$ between .86 and .97.

Return to the Problem Coding System. The Return to the Problem Coding System (RPCS; Gonçalves, Ribeiro, Santos, Gonçalves, \& Conde, 2009) is a qualitative system that analyzes the reemergence of the problematic self-narrative through RPMs immediately after the emergence of an IM. Previous studies using the RPCS (Gonçalves, Ribeiro, Stiles, et al., 2011; Ribeiro et al., 2012; Ribeiro, Cruz, Mendes, et al., 2012) reported a reliable agreement between judges on RPM coding, with a Cohen $\kappa$ between .88 and .93.

Protonarratives Coding System. The Protonarratives Coding System (PCS, Ribeiro, Gonçalves, \& Bento, 2010) analyzes the underlying theme of each IM, known as a protonarrative. The themes or protonarratives are identified from a consensus between coders, after the reading of all IMs from all the sessions. Thus far, PCS has been applied to Emotion-Focused Therapy (Bento, Ribeiro, Salgado, Gonçalves, \& Mendes, 2012), Constructivist Therapy (Ribeiroo et al., 2011), and Cognitive-Behavioral Therapy (Antunes, Santos, Ribeiro, \& Gonçalves, 2012), in different cases (e.g., major depression, survivors of partner violence).

\section{Procedure}

Outcome measures. The SCID-I (First et al., 2002) and SCID-II (First et al., 1997) were administered during the first meeting with both clients to assess comorbidity with other disorders that could be clinically more central than complicated grief. Concomitantly, in the first session, the Portuguese version of the ICG (Frade et al., 2009) was administered to screen for complicated grief symptoms. The ICG was then administered every fourth session and at 6-month follow-up. The BDI-II was also used in every fourth session and at follow-up, as depressive symptomatology has been identified as being related to grief distress (Bonanno \& Mancini, 2006). The same procedure was used for administration of the OQ-45.2 for screening of the client's psychological progress throughout therapy.

Emily was diagnosed with complicated grief, comorbid with major depression, as defined by the DSM-IV (American Psychiatric Association, 1994). She showed a significant clinical change at the end of therapy, according to the RCI analysis (see Jacobson \& Truax, 1991) of her pre to posttest scores on the ICG (from 42 to 11 , cutoff score 30 ), the BDI-II (from 26 to 8 , cutoff score 14.29) and the OQ-45.2 (from 73 to 38 , cutoff score 62). In the last follow-up session, 6 months after treatment termination, she scored 4 on the ICG, 8 on the BDI-II and 32 on the OQ- 45 .

Rose was also diagnosed with complicated grief, comorbid with major depression. She showed a considerable pre-post score reduction in the BDI-II (from 35 to 15 , cutoff score of 14.29) and in the OQ-45.2 (from 91 to 64, cutoff score of 62), maintaining the same scores until the last follow-up session. However, she maintained a clinical score on the ICG at Session 15 and follow-up (scores of 42 and 41, respectively, beginning with score of 55 at Session 1, cutoff score of 30). Thus, her depressive symptoms (assessed by the BDI-II) and her psychological functioning (assessed by the OQ-45.2) improved, but her grief symptomatology (assessed by the ICG) did not improve.

Despite research evidence suggesting comorbidity between complicated grief and posttraumatic stress disorder (PTSD; McDevitt-Murphy, Neimeyer, Burke, \& Williams, in press), neither Emily nor Rose met the criteria for a PTSD diagnosis.

\section{Process measures.}

IMCS: IMs training, coding, and reliability. The first and second authors (Judge 1 and 2, respectively) independently coded the transcripts of all the sessions of both cases using the IMCS (Gonçalves, Ribeiro, Mendes, et al., 2011). Both judges were unaware of client's clinical outcomes in all the instruments applied, that is, in the ICG, in the BDI-II, and in the OQ-45.2. As only Judge 1 had experience using the IMCS, Judge 2 completed a training procedure before initiating coding of these cases. A skilled external auditor supervised the training process. By the end of the training process Judge 2 was considered a reliable coder, with a Cohen $\kappa$ higher than .75 .

Judges discussed their understanding of the client's problems before the coding process to generate a consensual definition of the aspects of the problematic self-narrative, so that exceptions (IMs) could be coded. Subsequently, each session was independently coded in terms of types and salience of IMs. The salience index indicates the percentage of text in the session occupied by a specific IM and is computed by calculating the number of words involved in each type of IM divided by the total number of words in the transcript of the session. Sessions were coded sequentially, considering both therapist and client contributions, as we believe that the process of change is coconstructed (Neimeyer, 2009).

The percentage of salience agreement between judges was 84.2\% for Emily's case and $89.1 \%$ for Rose's case, reflecting a high degree of consensus regarding the number of words coded as IMs, across sessions. The agreement between judges for the specific types of IM, assessed with Cohen $\kappa$, was .96 for Emily's case 
and .91 for Rose's case, again indicating strong agreement among coders (Hill \& Lambert, 2004).

Return to the Problem Coding System: RPMs training, coding, and reliability. Judges 1 and 2 participated in the RPM coding procedure. Judge 1 had experience with coding RPMs. Judge 2 underwent a training process similar to that described for IMCS training.

RPMs coding comprised two sequential steps: (a) independent coding, and (b) resolving disagreements through consensus. The judges independently coded the transcripts of all sessions of both cases, analyzing the previously coded IMs for the presence or absence of RPMs. Reliability of identifying RPMs, assessed by Cohen к, was .80 for Emily's case and .79 for Rose's case. An external auditor, the third author of this study, also participated in the final RPM coding procedure, reviewing the decisions on RPMs coding made by the judges.

Protonarratives Coding System: Protonarratives coding procedures and reliability. Coding protonarratives involved consensual coding between judges 1 and 2, along with an auditing process (Hill et al., 2005) led by the third author. This phase was oriented by the question: "If this IM develops into a new self-narrative, what would be the main rule of this new self-version?" (Ribeiro et al., 2011). In both cases, we attempted to find the main theme or rule associated with the development of IMs, aggregating these themes into a sentence or word that designated the central protonarrative. Each successive IM was then compared with the identified protonarratives, looking for convergence or discrepancy. During this process, protonarratives were frequently reformulated to create a robust category capable of integrating the diversity of the new meanings. This procedure was based on grounded theory analysis (Fassinger, 2005). Each protonarrative's salience was calculated as the sum of the salience of the IMs in which they emerged, for each session. The mean salience of all protonarratives throughout the process was computed. Finally, the global percentage of IMs with RPMs was calculated separately for each protonarrative.

\section{Results}

\section{IMs and RPMs Across Therapy}

Emily's overall salience of IMs throughout the therapeutic process was $30.0 \%$, with reflection and reconceptualization being the most salient IMs (15.2\% and 8.5\%, respectively). In Rose's case, IMs occupied $25.8 \%$ of the entire therapeutic conversation, with reflection also being the most salient IM (22.9\%). The main difference in IM patterns between Emily and Rose was in reconceptualization, which appeared as the second most salient IM in the final phases of Emily's therapeutic process (8.5\%), but was infrequent in Rose's case $(0.7 \%)$. Finally, action, protest, and performing change IMs were infrequent in both cases (with a salience $<3.0 \%$ ).

The total percentage of RPMs was $33.5 \%$ in Emily's case and $41.7 \%$ in Rose's case. In previous studies (Ribeiro, Cruz, Mendes, et al., 2012; Ribeiro, Mendes, Angus, et al., 2012), the percentage of RPMs was between $20 \%$ and $40 \%$. Reflection, the most salient IM in both cases, was also the IM with the highest percentage of RPMs, representing 89.4\% of total RPMs in Emily's case and $87.7 \%$ in Rose's case.

In both cases, the frequency of RPMs was significantly associated with the frequency of IMs. A time-series analysis using Simulation Modeling Analysis (SMA; Borckardt et al., 2008), a method for assessing the statistical significance of sequential observations in data series, indicated a cross-correlation at lag 0 between IMs and RPMs of .75 ( $p=.001)$ in Emily's case and .79 $(p=.001)$ in Rose's case (Bonferroni correction was used). Despite the high correlation between IMs and RPMs, the cases showed distinct trajectories of RPMs from the middle stages of the treatment to the end of treatment. In Emily's case, as presented in Figure 1, the frequency of RPMs progressively decreased from Session 11 to the final session, and this decrease persisted 6 months later at follow-up. In Rose's case, as shown in Figure 2, the frequency of RPMs decreased in Session 15 but increased in the follow-up session.

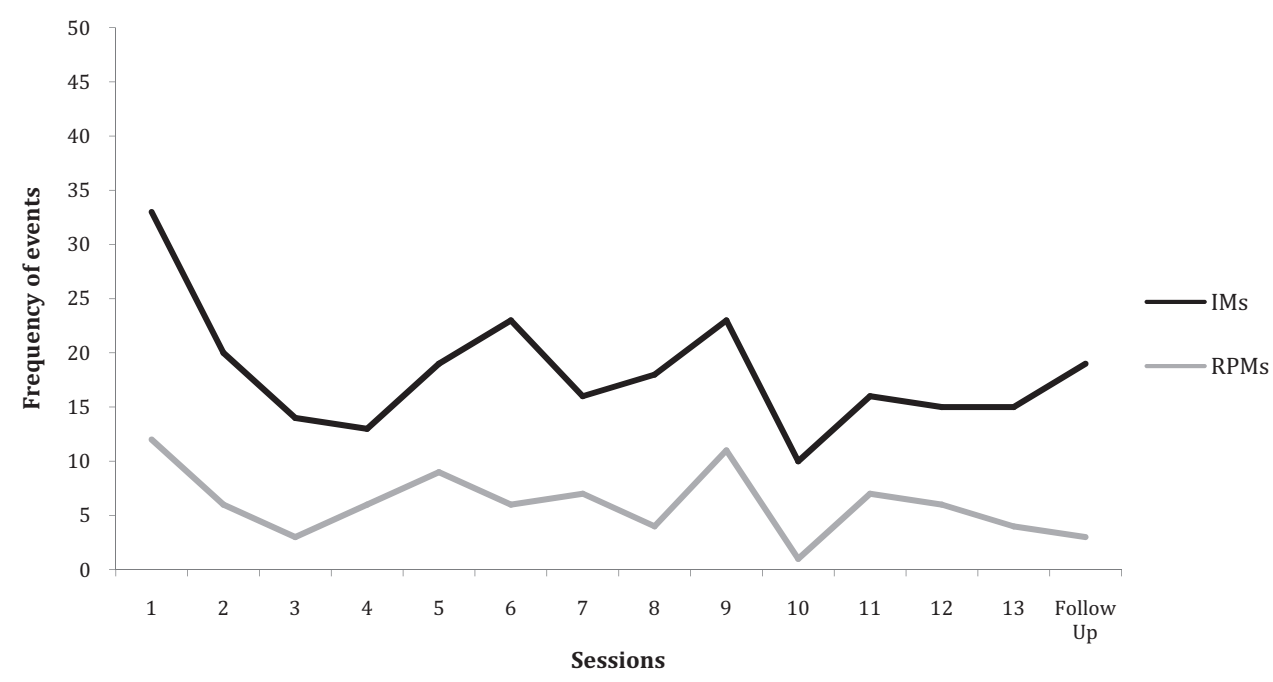

Figure 1. Frequency of IMs and RPMs in Emily's case. 


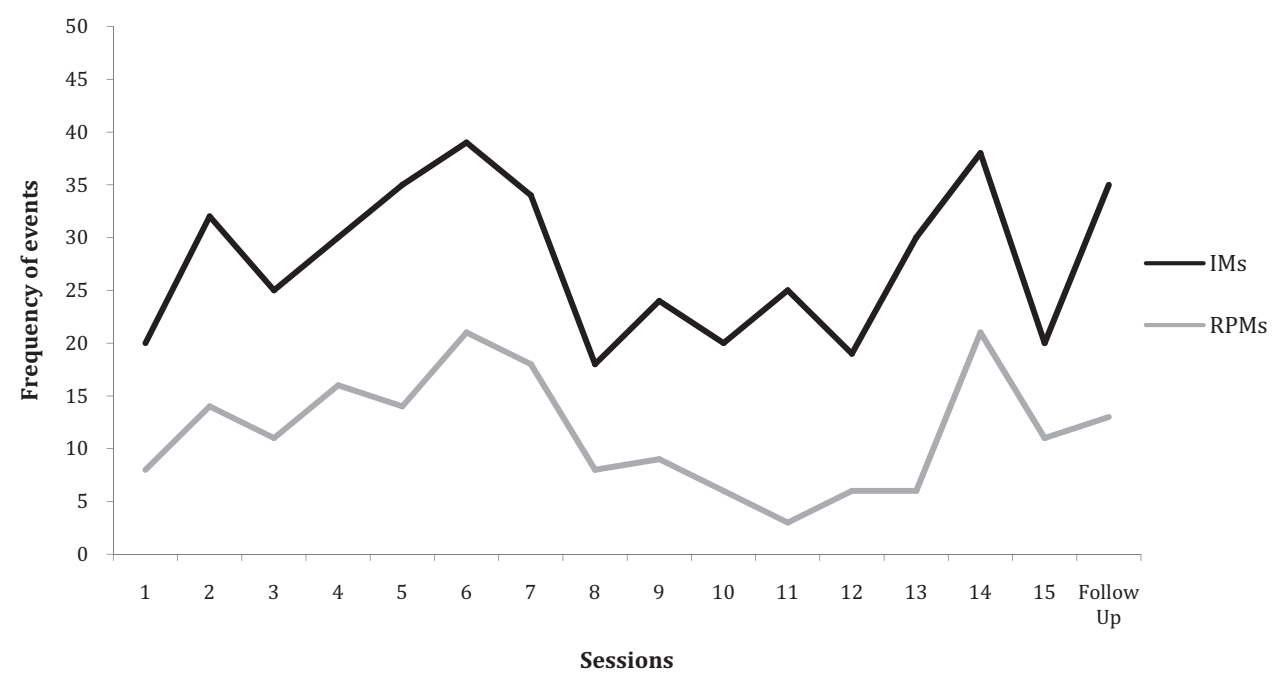

Figure 2. Frequency of IMs and RPMs in Rose's case.

\section{Protonarratives Across Therapy}

In Emily's case, we identified four protonarratives, listed here according to the order in which they appeared in therapy: "Acceptance of Death" (mean salience $=11.2 \%$ ), "Proactivity" (mean salience $=17.8 \%$ ), "Integration" (mean salience $=45.8 \%)$, and "New Investments" (mean salience $=25.2 \%$ ). "Acceptance of Death" consisted of IMs in which Emily positioned herself toward a more flexible understanding of death, considering, for example, the ways death could be beneficial to ill persons as a relief from pain, thus reformulating her grandmother's death as a release from pain. "Proactivity" designated Emily's proactive search for reorganization in her life, such as focusing on the daily experiences that genuinely gave her pleasure (e.g., cultivating flowers), strength, and capacity to work (in opposition to her self-image as an immobilized, depressed, and fragile person) and her positive relationship with her daughter, including the way in which their relationship motivated her to move forward in life. "Integration" was associated with Emily's elaboration on the construction of a healthier relationship with her grandmother, through a more symbolic, rather than physical, connection (Field, 2006; Field, Gao, \& Paderna, 2005). This elaboration prompted a less painful experience of loss, and Emily gradually relinquished guilt for not having kissed her grandmother on the day of her funeral. Thus, Emily started to contemplate a more compassionate position toward herself regarding her grandmother, expressed through an unsent letter addressing this event. Consequently, as the therapeutic process evolved, she became more comforted by positive memories of her grandmother in her life (e.g., remembering her grandmothers culinary instructions each time she sees the cooking utensils her grandmother gave her). Finally, "New Investments" was associated with Emily's new projects as a consequence of her change (e.g., obtaining a drivers license, working at a coffee shop). The evolution of Emily's protonarratives throughout therapy is presented in Figure 3. In the first phase of her treatment, "Proactivity" and "Acceptance of Death" were the most salient and stable protonarratives, and they decreased in salience as the middle phase of the therapy was reached. "Integration" emerged for the first time in Session 2 , and became the most salient protonarrative in the middle phase of therapy. In the final phase, "Integration" and "New Investments" were the most salient protonarratives.

In Rose's case, we identified three protonarratives: "SelfForgiveness" (mean salience $=18.2 \%$ ), "Proactivity" (mean salience $=36.5 \%)$, and "Integration" ( mean salience $=45.3 \%)$. "Self-forgiveness" consisted of IMs associated with Rose's higher tolerance regarding the decisions she made in the past involving her son and husband. Specifically, through a metaphor of a "court trial," Rose (the judge) considered alternative "verdicts" to her life by imagining the voices of her lost loved ones (or others relatives and friends) as "voices of defense against guilt," organizing a scenario where the guilt's voice was not the only one to be heard. This scenario is illustrated in the following excerpt of a letter she wrote from the perspective of her son: "Mother, you did everything you could for me, you were with me at the hospital, you left your work. . . now you need to move on and also think about my sister." "Proactivity" incorporated Rose's experiences of well-being, resulting from her proactive search for life reorganization (e.g., computer classes, yoga). This theme also incorporated her intentions to fight for the happiness of her daughter, which motivated her to move forward in life. Finally, "Integration" incorporated Rose's investment in the construction of more adaptive less painful relationships with her son and husband (e.g., "I want to have them in my life in a different way, it's very difficult to sustain this pain everyday"). Through exploration of the "court trial" metaphor in "Self-Forgiveness," Rose gradually became more tolerant of herself, allowing the emergence of healthier memories of her lost ones, not only memories ruled by pain. Therefore, from the middle to the final phases of therapy, "Integration" began to incorporate not only her attempts to process her grief in a specific way but also the effects of these efforts, as she started to notice a more peaceful presence of them in her life (e.g., "Sometimes when some of my friends invite me to participate in activities such as walking in the city, I almost feel like they [her son and husband] are saying to me 'go, it's good for you, don't be so sad, we are fine"'). The evolution of Rose's protonarratives throughout therapy is presented in Figure 4. In general, "Proactivity" and "Self- 


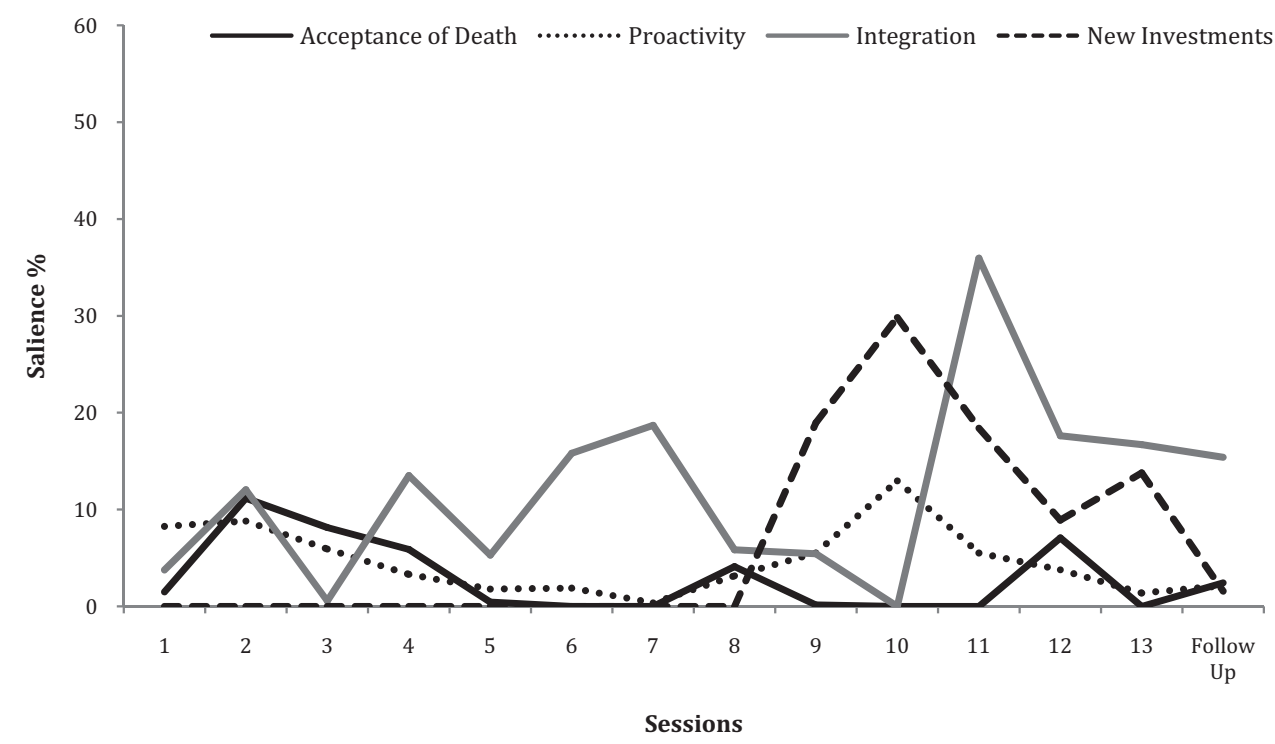

Figure 3. Salience of protonarratives in Emily's case.

Forgiveness" were the most salient themes in the initial phase of the process. From the middle phase to the final phase, "Integration" and "Proactivity" became the most salient protonarratives.

\section{Protonarratives and RPMs Across Therapy}

Table 2 presents a cross-correlation analysis at lag 0 between the frequency of IMs of each protonarrative and the total frequency of RPMs of each case. It was conducted with the SMA (Borckardt et al., 2008; with a Bonferroni correction for multiple comparisons). In Emily's case, the only protonarrative in which the IMs were significantly correlated with RPMs was "Integration," which was also the most salient protonarrative of the entire case. In Rose's case, IMs from both "Proactivity" and "Self-Forgiveness" were significantly correlated with RPMs. In "Integration," the most salient protonarrative of Rose's case, IMs were not significantly correlated with RPMs.

In the following section we analyzed the protonarratives in which RPMs were correlated with the emergence of IMs, given that these are the protonarratives in which ambivalence was stronger.

\section{Descriptive Analysis of the Association Between Protonarratives and RPMs}

In Emily's case, "Integration" emerged during the first session and was the most salient theme across therapy. Additionally, it was the theme most associated with the emergence of RPMs. As

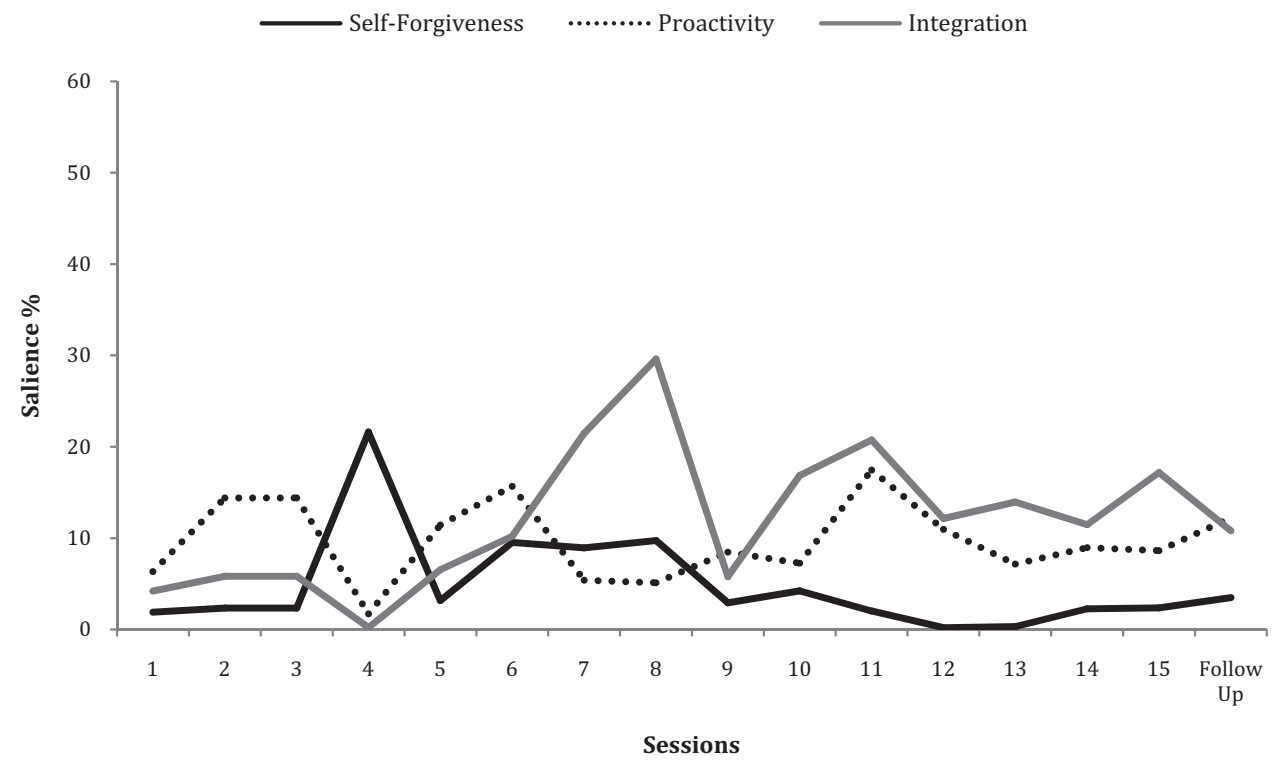

Figure 4. Salience of protonarratives in Rose's case. 
Table 2

Mean Salience of Protonarratives Throughout the Process and Cross-Correlation Analysis at Lag $O$ Between the IMs of Each Protonarrative and the Total Frequency of RPMs in Both Cases

\begin{tabular}{lll}
\hline $\begin{array}{c}\text { Clients and } \\
\text { protonarratives }\end{array}$ & Protonarratives Salience & $\begin{array}{r}\text { Cross-correlation protonarrative IMs } \times \text { RPMs; } \\
\text { Bonferroni correction for multiple comparisons }\end{array}$ \\
\hline $\begin{array}{l}\text { Emily } \\
\text { Integration }\end{array}$ & $45.8 \%$ & $r=.51 ; p=.02^{*}$ \\
$\quad$ New investments & $25.2 \%$ & $r=.13 ; p=.31$ \\
Proactivity & $17.8 \%$ & $r=.28 ; p=.14$ \\
Acceptance of death & $11.2 \%$ & $r=.19 ; p=.24$ \\
Rose & $45.3 \%$ & $r=.08 ; p=.39$ \\
Integration & $36.5 \%$ & $r=.64 ; p=.004^{* * *}$ \\
Proactivity & $18.2 \%$ & $r=.62 ; p=.007^{* * *}$ \\
Self-forgiveness & &
\end{tabular}

presented previously, its contents were associated with Emily's investments in a more symbolic relationship with her grandmother, one that was less ruled by pain and guilt. For example, in Session 7, after the therapist's suggestion to reopen dialogue with her grandmother and to share with her the guilt Emily had felt since her funeral, by not having kissed her lifeless body, Emily began reassessing the experience in a more flexible way: "Maybe I was protecting myself, and also my brother took me away from the church, it was not only my decision." She continued this elaboration in Session 8, using a visualization of a more tolerant position of her grandmother, as shown in the following excerpt: "I think that she would accept my apologies. . . she would consider that it is necessary to have a lot of courage to do it. Maybe she ... in fact she didn't go to my uncle's funeral (her son), probably she also didn't have the courage to do it." Nevertheless, Emily's elaboration of "Integration" was frequently interrupted with RPMs, through which she mainly reasserted the guilt of not having kissed her grandmother on the day of her funeral. This movement reinforced the distress of physical separation, attenuating her investment in a more representational or symbolic bond with her grandmother. To illustrate this point, let us consider the following example from Session 8, in which she reflected on the way she felt regarding the activity of reopening dialogue with her grandmother: "It was a relief to have been able to say it to her, asking her forgiveness (emergence of an IM [Integration]) but ... it's not the same thing ... I should have given her a kiss. It's not that she could felt it, but I think it would have been important for her to have taken it" (RPM - [Guilt]_IM's attenuation). The attenuation of IMs through RPMs was recurrent in "Integration," especially in the initial and middle phases of the therapeutic process.

In Rose's case, "Proactivity" was significantly correlated with the emergence of RPMs. Attenuation of "Proactivity" was mainly associated with Rose's reiteration of her lack of right to move forward in life, reaffirming the recurrent problematic self-narrative ruled by helplessness and guilt. It is illustrated in the following excerpt from Session 6, in which Rose describes the way she felt when she took a ride with her daughter to the nearby city:

Client (C): Ah, I was hesitant, 'should I go or not?' Well, I end up convincing me to go, I felt some kind of strength or something saying, 'go, it will be good for you'

Therapist (T): What was the meaning of that strength for you?

C: Well, it's like feeling that I shouldn't hold on to negative feelings but trying other things, other moments that offer me a kind of a way out (emergence of an IM [Proactivity]). Well, it's not that everything was fine because the guilt was always present (RPM[Helplessness and Guilt]_IM's attenuation).

"Self-Forgiveness" was also significantly correlated with the emergence of RPMs, through the reiteration of guilt, along with a feeling of incompetence regarding the decisions she took in the past involving her son and husband, as illustrated in the following excerpt from Session 8 regarding seeking treatment for her son's cancer only in Portugal:

$C$ : There are moments when I can hear a voice saying, 'you couldn't do anything more' or 'you did everything you could, the doctors said that the medical protocol used here (in Portugal) was the same from other countries so you did the right thing.'

T: Uh-huh.

C: Sometimes I can hear these voices, you know?

T: The Defense voices....

$C$ : Yes, saying, 'what more could you have done?' (emergence of an IM [Self-Forgiveness]) but then there comes the other voice (guilt) up to me saying 'maybe I could have done more and I didn't, maybe the treatment in other countries, like in the U.S., could have saved him' (RPM-[Guilt]-IM's attenuation).

\section{Discussion}

A growing number of psychotherapy studies using the IMCS and the RPCS direct our attention to the role of IMs in the transformation of problematic self-narratives (Alves et al., 2012; Gonçalves, Mendes, Ribeiro, et al., 2010; Matos et al., 2009; Mendes et al., 2010; Santos et al., 2009), and to the role of the RPMs in the maintenance of problematic self-narratives (Gonçalves, Ribeiro, Stiles, et al., 2011; Ribeiro, Cruz, Mendes, et al., 2012; Ribeiro, Mendes, Angus, et al., 2012). This study explores the transformation (IMs) and maintenance (RPMs) of problematic self-narratives in two cases of constructivist grief psychotherapy, analyzing the main themes (protonarratives) involved in this change process.

The results show that the overall salience of IMs is slightly higher in Emily's case (30.0\%) than in Rose's case (25.8\%). In both cases, reflection is the most salient IM, with a total percentage of $15.2 \%$ in Emily's case and $22.9 \%$ in Rose's case. The main difference in the pattern of IMs between the two cases is in reconceptualization, which is the second most salient IM in Emily's case $(8.5 \%)$, being infrequent in Rose's case $(0.7 \%)$. The total 
percentage of RPMs, in turn, is slightly higher in Rose's case (41.7\%) than in Emily's case (33.5\%). An SMA analysis (Borckardt et al., 2008) shows that the progression of IMs and RPMs is significantly correlated at lag 0 in both cases, rising to $.75(p=$ $.001)$ in Emily's case and $.79(p=.001)$ in Rose's case. These cross-correlations are higher when compared with a previous study examining IMs and RPMs in a sample of Emotion-Focused Therapy of Depression (Ribeiro, Mendes, Angus, et al., 2012), in which the cross-correlation at lag 0 was .39 ( $p \leq .001)$.

Despite the significant association between IMs and RPMs in both grief cases, there is a distinct evolution of RPMs at the end of therapy. Whereas in Emily's case the frequency of RPMs shows a progressive decrease from Session 11 to follow-up, there is an increasing and irregular movement of RPMs at the end of Rose's therapy. This is congruent with previous studies using the RPCS in Emotion-Focused Therapy and Client-Centered Therapy, in which the evolution of RPMs tends to decrease in GO cases and increases or remains stable and high in PO cases (Ribeiro, Cruz, Mendes, et al., 2012; Ribeiro, Mendes, Angus, et al., 2012). In both cases, "Integration" is the protonarrative that induces greater emergence of IMs. Thus, approximately $45 \%$ of the time when an IM is elaborated, it is related to the construction of a healthier and less painful relationship with a lost one. Curiously, the IMs of "Integration" are significantly correlated with RPMs in Emily's case (the case with the significant clinical change) and are not significantly correlated in Rose's case (the case without significant clinical changes in grief symptomatology). In fact, "Integration" is the only theme of Rose's case in which the IMs are not significantly correlated with the emergence of RPMs. We speculate that this result may be associated with the distinct ways through which the clients elaborated this protonarrative from the beginning of therapy. This protonarrative is associated with the clients' reconstruction of a more symbolic connection with their lost ones, becoming also capable of finding a new comfort beyond physical contact (Field et al., 2005). When Emily began therapy, she described herself as a depressive person who could not accept the idea of human death and physical vanishing. During the first and middle phases of therapy, she described herself as being confused regarding the way she could accept the loss of her grandmother in a more symbolic way. Accordingly with this confusion, she recurrently attenuated "Integration" by validating the way she felt guilty for not having reached her grandmother physically (with a kiss) on the day of her funeral. However, it is interesting to note that during the final phase of the therapy, Emily begins to elaborate "Integration" though a metareflexive position (through the use of reconceptualization IMs), by describing the way she created a new concept of human death (as a release from illness) and how it helped her accept her grandmother's death. Congruent with this innovative understanding of her change process, she starts reassessing her grandmother's existence through positive memories (e.g., cooking objects). This change suggests that, at this point, Emily was able to find positive comfort through a more symbolic representation of her grandmother. This achievement seems to be consistent with the assumptions proposed by Gonçalves, Matos, and Santos (2009) regarding the emergence of reconceptualization IMs in therapy. According to these authors, its emergence is associated with clients' reintegration of painful experiences into a new self-narrative, as they begin to see themselves as the principal authors of their change process. It is also interesting to note that the frequency of RPMs tends to decrease in the final phase of Emily's therapy. We speculate that despite the significant correlation between IMs of "Integration" and RPMs, the emergence of reconceptualization may have stimulated a more flexible perception of Emily's ability to change, fostering a decrease in ambivalence, which is congruent with findings from previous studies (Cunha, Gonçalves, Valsiner, Mendes, \& Ribeiro, in press; Cunha, Gonçalves, \& Valsiner, 2011; Gonçalves, Ribeiro, Stiles, et al., 2011). It is also congruent with previous bereavement studies indicating the capacity to integrate loss as a strong predictor of successful grief adaptation (Holland, Currier, \& Neimeyer, 2006; Holland \& Neimeyer, 2010; Keesee et al., 2008), as the client progressively transforms the previous relationship with the deceased into a more symbolic and comfortable connection (Neimeyer, 2006a).

In Rose's case, in contrast, IMs from "Integration" are not significantly correlated with the emergence of RPMs and did not consistently progress to an elaboration of reconceptualization. This theme seems to be consistent with the way Rose describes the objective that brings her to therapy: to have her son and husband in her life in a different way. Her search for a symbolic connection with her son and husband seems to have begun before therapy, as in the first session, she described the way she obtained some comfort from reading grief books and participating in self-help groups for bereaved parents. Perhaps the consistency of "Integration" with her previous attempts to maintain bonds with her son and husband may help us understand why she tends to elaborate this theme with lower levels of ambivalence, feeling less compelled to protect herself from the anxiety of change (Engle \& Holiman, 2002; Frankel \& Levitt, 2009). As "Integration" focuses on her investment in her loved ones, she sees herself struggling for their presence in her life. In contrast, "Self-Forgiveness" and "Proactivity" (themes highly correlated with RPMs) incorporate the investment of new life goals and priorities - beyond the physical presence of her son and husband-through the release of pain and guilt. Perhaps this discontinuity with her previous story of loss may be felt as an abandonment of her loved ones, as she may understand her pain as part of the terms of forming a new attachment to them (Rando, 2012). In this sense, in the majority of times in which she elaborated "Self-Forgiveness" and "Proactivity," she immediately felt compelled to reaffirm the way she was suffering by having lost them, protecting herself from the guilt of giving them up. This ambivalence seems to be in line with the assumptions postulated by Rando (2012), indicating that investment in life reorganization with lower levels of pain can be difficult for some grief clients, manifesting as a type of resistance in therapy. Finally, even though in Rose's case "Integration" is not significantly correlated with the emergence of RPMs, this condition alone (elaboration of a theme with lower levels of ambivalence) is not sufficient for the creation of an alternative self-narrative. Therefore, although in the final phases of Rose's process "Integration" incorporates real episodes of a more peaceful presence of her loved ones in her life, the absence of reconceptualization seems to indicate a fragile sense of authorship regarding the way this transformation process occurs. Given that, we hypothesize that until the emergence of a metaperspective elaboration on the change processes (through reconceptualization IMs), the absence of ambivalence may indicate that the theme does not sufficiently disturb the client's previous meaning system, and does not necessarily evolve into an innovative meaning reconstruction. This validates, again, 
the centrality of reconceptualization on the construction of a more stable and coherent alternative self-narrative (Cunha, Gonçalves, Valsiner, et al., in press; Gonçalves, Matos, Santos, 2009). In conclusion, the marked absence of reconceptualization in all the themes that emerge in Rose's therapy may suggest that over the 15 sessions she did not form a stable integration of the most painful aspects of her experience into a more flexible self-narrative. Considering the fact that "Integration" (the most prevalent theme of the entire process) focuses on bond maintenance with her lost ones, these results direct our attention to the way this investment may facilitate or inhibit the bereavement adaptation. In fact, several studies have shown that when the survivor is unable to integrate loss in a more comforted way, the postmortem connection with the deceased may instigate higher levels of distress (Neimeyer, Baldwin, \& Gillies, 2006).

Finally, the consideration of the distinct features associated with each grief story may also help us understand the individual processes of loss integration and postmortem attachment. One of the features that may be taken into consideration is the amount of time to integrate loss. For example, Field and Friedrichs (2004) found that widows who were grieving for longer than 2 years showed a more comforting relationship with the deceased when compared with widows whose husbands died more recently. In Rose's case, in addition to the loss of her son 3 years ago, she is also dealing with the recent and tragic loss of her husband, which may further challenge the integration of loss in a scenario of grief overload (Neimeyer \& Holland, 2006). Likewise, circumstances related to the death of Rose's relatives might also impact the distinctiveness of her pattern of change. Recent research suggests that the losses associated with untimely (e.g., loss of a child) or violent (e.g., fatal accidents) deaths may increase the risk of complicated grief symptomatology (Lichtenthal, Cruess, \& Prigerson, 2004; Stroebe, Schut, \& Stroebe, 2007), as they are associated with greater difficulty to construct a healthier understanding of these events (Currier et al., 2007; Currier, Holland, \& Neimeyer, 2006). Therefore, in conjunction with the recognition of client's ambivalence or self-protection throughout the change process (Engle \& Holiman, 2002), the therapist may also contemplate the distinct risk factors of each grief client as important aspects of the therapy (Keese et al., 2008; Stroebe, Folkman, Hansson, \& Schut, 2006).

Although only Emily showed a significant clinical change in all outcome measures at the end of therapy (considering the RCI), Rose showed symptomatic improvements, especially in the BDI-II and in the OQ-45.2, decreasing 14 points in the ICG from pre- to post-treatment phases. This may indicate that the recurrence of ambivalence may not necessarily inhibit the change process, even though it could inform the therapist about the most painful and key aspects that need to be further worked on in therapy. For example, if we consider the Dual Process of Bereavement from Stroebe and Schut (1999), it is proposed that the griever's choice to avoid negative emotions as pain, sadness, anger, guilt (as a time off on the loss-orientated response) may potentiate the process of life restoration (investing in more positive emotions, plans, projects). In this sense, we could look at Emily and Rose's RPMs (both in "Integration" and "Proactivity" protonarratives) as an evidence of this process of back and forth from loss integration and life reorganization, respectively. According to this line of reasoning, the emergence of ambivalence in grief psychotherapy could reflect the way clients respect their own timing of change toward grief adaptation, which also needs to be integrated in the therapeutic process.

A final consideration regarding the results of this study addresses the fact that, in 15 sessions, Rose achieved a considerable change in depression but remained relatively stable on complicated grief symptomatology, pointing a distinct timing of change between these two problematics. We hypothesize that this result may be associated with the way she organized an active search for alternative ways of grieving, focused on "being strong and present" for her daughter. Being committed with this goal, she tried different activities (e.g., support groups, grief books) and entered therapy. It may be the case that this active interest and investment in herself and in her daughter's well-being (different from the general loss of interest and sense of worthless in depression) had resonance on her depressive symptomatology. Furthermore, despite the clinical grief symptomatology at the end of therapy, she also decreased 14 points in the ICG (even though not as a recovered case), which may indicate a healthy evolution in her grief symptomatology as well, but in a different timing from depression. It seems to be consistent with recent research suggesting "complicated grief" and "depression" as different problematics (Bonanno et al., 2007; Lichtenthal et al., 2004).

\section{Limitations}

One of the main limitations of this study is the fact that the cases have very distinct features regarding the types of loss brought to therapy, which may restrain any attempt to compare the data between them. Also, the results are based only on two clients, followed only by one therapist in a nonmanualized intervention, which restricts generalization. In this sense, future studies should be conducted with other cases and samples of grief therapy, followed by different therapists and even with different therapeutic modalities. Another limitation of this study is related to the fact that the exploration of clients' narrative processes along therapy makes difficult for judges to be completely unaware of clients' clinical progression over time. In this sense, despite the fact that both judges were unaware of clients' clinical outcomes in all the instruments used in this study, this does not completely guarantee a total unawareness of their distinct patterns of change.

Finally, we also consider that the results of this study regarding the association between clients' clinical and narrative change must be carefully interpreted. That is, we consider that it is not possible to establish a causal relationship between the elaboration of IMs, RPMs, and clients' clinical progression over time. Given the nature of this research design, it is not possible to rule out the contribution of third variables that both explain symptoms' change and the patterns of IMs and RPMs.

Despite these limitations, we believe that this study has provided relevant information regarding the way two different grief clients created innovation and addressed ambivalence, and how these different narrative constructions influenced both the emergence of a healthier story of loss and resulted in symptomatic improvement.

\section{Future Research}

Further research is needed regarding the role of ambivalence in grief psychotherapy, exploring how clients maintain and transform the stories they bring to therapy and how ambivalence may affect 
the processes of loss integration and life reorganization. Specific case studies addressing the particularities of each grieving process (e.g., time since loss, death circumstances) may provide a deeper understanding of the individual processes of "meaning reconstruction in the experience of loss" (Neimeyer, 2001), and how these narrative processes may facilitate differentiation between beneficial versus problematic attachment with the deceased.

Finally, the exploration of therapists' involvement in the coconstruction of change would also be relevant. Although this study did not focus on the therapist contribution on self-narratives transformation (through IMs) or maintenance (through RPM), a recent study by Ribeiro, Ribeiro, Loura, et al. (2012) suggests that the emergence of RPMs (or ambivalent responses) tends to appear when the therapist proposes more challenging interventions, trying to intensify the emergence of IMs. Interpreted as a less supportive movement regarding clients' difficulties, it seems to stimulate the emergence of RPMs, perceived as a response of self-protection (Engle \& Holiman, 2002) against uncertainty or unfamiliarity (brought by IMs). Regarding this form of resistance in therapy, the authors suggest that the therapist needs to invest in less challenging interventions, being, instead, more empathetic with client's problematic stories and difficulties. Although this association between therapist's interventions and the emergence of RPMs needs to be further studied, it seems to be relevant on addressing the nature and role of RPMs as a coconstruction between client and therapist.

\section{References}

Alves, D., Mendes, I., Gonçalves, M., \& Neimeyer, R. A. (2012). Innovative moments in grief therapy: Reconstructing meaning following perinatal death. Death Studies, 36, 795-818. doi:10.1080/07481187 .2011 .608291

American Psychiatric Association. (1994). Diagnostic and Statistical Manual of Mental Disorders (4th ed.). Washington, DC: American Psychiatric Association.

American Psychiatric Association. (2000). Diagnostic and Statistical Manual of Mental Disorders (4th ed., Text Revision; DSM-IV-TR). Washington, DC: American Psychiatric Association.

Antunes, A., Santos, A., Ribeiro, A., \& Gonçalves, M. (2012). Protonarratives in cognitive-behavioral therapy. Manuscript in preparation.

Beck, A. T., Steer, R. A., \& Brown, G. K. (1996). Manual for Beck Depression Inventory II. San Antonio, TX: Psychological Corporation.

Bento, T., Ribeiro, A. P., Salgado, J., Gonçalves, M. M., \& Mendes, I. (2012). Narrative model of therapeutic change: An exploratory study tracking innovative moments and protonarratives using state space grids. Manuscript in preparation.

Boelen, P. A., \& Prigerson, H. G. (2007). The influence of symptoms of prolonged grief disorder, depression, and anxiety on quality of life bereaved adults: A prospective study. European Archives of Psychiatry and Clinical Neuroscience, 257, 444-452. doi:10.1007/s00406-0070744-0

Bonanno, G. A. (2004). Loss, trauma and human resilience. American Psychologist, 59, 20-28. doi:10.1037/0003-066X.59.1.20

Bonanno, G. A., Neria, Y., Mancini, A., Coifman, K. G., Litz, B., \& Insel, B. (2007). Is there more to complicated grief than depression and posttraumatic stress disorder? A test of incremental validity. Journal of Abnormal Psychology, 116, 342-351. doi:10.1037/0021-843X.116.2 .342

Bonanno, G. A., Wortman, C. B., \& Nesse, R. M. (2004). Prospective patterns of resilience and maladjustment during widowhood. Psychology and Aging, 19, 260-271. doi:10.1037/0882-7974.19.2.260
Bonnano, G. A., \& Mancini, A. D. (2006). Bereavement-related depression and PTSD: Evaluating interventions. In L. Barbanel \& R. J. Sternberg (Eds.), Psychological interventions in times of crisis (pp. 37-55). New York: Springer Publishing Co.

Borckardt, J. J., Nash, M. R., Murphy, M. D., Moore, M., Shaw, D., \& O'Neil, P. (2008). Clinical practice as natural laboratory for psychotherapy research: A guide to case- based time-series analysis. American Psychologist, 63, 77-95. doi:10.1037/0003-066X.63.2.77

Bruner, J. S. (1990). Acts of meaning. Cambridge: Harvard University Press.

Bruner, J. (2002). Making stories: Law, literature, life. New York: Farrar, Straus and Giroux.

Coelho, R., Martins, A., \& Barros, H. (2002). Clinical profiles relating gender and depressive symptoms among adolescents ascertained by the Beck Depression Inventory II. European Psychiatry, 17, 222-226. doi: 10.1016/S0924-9338(02)00663-6

Coleman, R. A., \& Neimeyer, R. A. (2010). Measuring meaning: Searching for and making sense of spousal loss in later life. Death Studies, 34, 804-834. doi:10.1080/07481181003761625

Cunha, C., Gonçalves, M., Hill, C. E., Sousa, I., Mendes, I., Ribeiro, A., ... Greenberg, L. S. (in press). Therapist interventions and client innovative moments in emotion-focused therapy for depression. Psychotherapy.

Cunha, C., Gonçalves, M. M., \& Valsiner, J. (2011). Transforming selfnarratives in psychotherapy: Looking at different forms of ambivalence in the change process. In R. Jones \& M. Morioka (Eds.), Jungian and dialogical self perspectives (pp. 43-66). Basingstoke, UK: Palgrave Macmillan.

Cunha, C., Gonçalves, M. M., Valsiner, J., Mendes, I., \& Ribeiro, A. P. (in press). Reharsing renewal of identity: Reconceptualization on the move. In M. C. Bertau, M. M. Gonçalves, \& P. Raggat (Eds.), The development of the dialogical self: Advances in cultural psychology (series editor: Jaan Valsiner). Charlotte, NC: IAP, Information Age Publications.

Currier, J. M., Holland, J., Coleman, R., \& Neimeyer, R. A. (2007). Bereavement following violent death: An assault on life and meaning. In R. Stevenson \& G. Cox (Eds.), Perspectives on violence and violent death (pp. 175-200). Amityville, NY: Baywood.

Currier, J. M., Holland, J. M., \& Neimeyer, R. A. (2006). Sense-making, grief, and the experience of violent loss: Toward a mediational model. Death Studies, 30, 403-428. doi:10.1080/07481180600614351

Currier, J. M., \& Neimeyer, R. A. (2006). Fragmented stories: The narrative integration of violent loss. In E. K. Rynearson (Ed.), Violent death: Resilience and intervention beyond the crisis (pp. 85-100). New York: Routledge/Taylor \& Francis Group.

Del-Ben, C. M., Vilela, J. A. A., Crippa, J. A. de, S., Hallak, J. E. C., Labate, C. M., \& Zuardi, A. W. (2001). Confiabilidade da "Entrevista Clínica Estruturada para o DSM-IV-Versão Clínica" traduzida para o português. Revista Brasileira de Psiquiatria, 23, 156-159. doi:10.1590/ S1516-44462001000300008

Dimaggio, G. (2006). Disorganized narratives in clinical practice. Journal of Constructivist Psychology, 19, 103-108. doi:10.1080/ 10720530500508696

Engle, D., \& Holiman, M. (2002). A gestalt-experiential perspective on resistance. JCLP/In Sessions: Psychotherapy in Practice, 58, 175-183.

Fassinger, R. (2005). Paradigms, praxis, problems, and promise: Grounded theory in counseling psychology research. Journal of Counseling Psychology, 52, 156-166. doi:10.1037/0022-0167.52.2.156

Field, N. P. (2006). Continuing bonds in adaptation to bereavement: Introduction. Death Studies, 30, 709-714. doi:10.1080/ 07481180600848090

Field, N. P., \& Friedrichs, M. (2004). Continuing bonds in coping with the death of a husband. Death Studies, 28, 597-620. doi:10.1080/ 07481180490476425 
Field, N. P., Gao, B., \& Paderna, L. (2005). Continuing bonds in bereavement: An attachment theory based perspective. Death Studies, 29, 277299. doi:10.1080/07481180590923689

Field, N. P., Nichols, C., Holen, A., \& Horowitz, M. J. (1999). The relation of continuing attachment to adjustment in conjugal bereavement. Journal of Consulting and Clinical Psychology, 67, 212-218. doi:10.1037/ 0022-006X.67.2.212

First, M. B., Gibbon, M., Spitzer, R. L., Williams, J., \& Benjamin, L. (1997). Structured Clinical Interview for DSM-IV Axis II Personality Disorders: SCID-II. Washington, DC: American Psychiatric Press Inc.

First, M. B., Spitzer, R. L., Gibbon, M., \& Williams, J. B. W. (2002). Structured Clinical Interview for DSM-IV-TR Axis I Disorders, research version, non-patient edition (SCID-I/NP). New York: New York State Psychiatric Institute, Biometrics Research.

Frade, B., Rocha, J., Sousa, H., \& Pacheco, D. (2009). Validation of Portuguese version for Inventory of Complicated Grief. Oslo, Norway: European Congress of Traumatic Stress.

Frankel, Z., \& Levitt, H. M. (2009). Clients experiences of disengaged moments in psychotherapy: A grounded theory analysis. Journal of Contemporary Psychotherapy, 39, 171-186. doi:10.1007/s10879-0089087-z

Gonçalves, M. M., Matos, M., \& Santos, A. (2009). Narrative therapy and the nature of "innovative moments" in the construction of change. Journal of Constructivist Psychology, 22, 1-23. doi:10.1080/ 10720530802500748

Gonçalves, M. M., Mendes, I., Cruz, G., Ribeiro, A., Angus, L., \& Greenberg, L. (2012). Innovative moments and change in client-centered therapy. Psychotherapy Research, 22, 389-401. doi:10.1080/10503307 .2012 .662605

Gonçalves, M. M., Mendes, I., Ribeiro, A., Angus, L., \& Greenberg, L. (2010). Innovative moments and change in emotional focused therapy: The case of Lisa. Journal of Constructivist Psychology, 23, 1-28. doi:10.1080/10720537.2010.489758

Gonçalves, M. M., \& Ribeiro, A. P. (2012). Therapeutic change, innovative moments and the reconceptualization of the self: A dialogical account. International Journal of Dialogical Science, 6, 81-98.

Gonçalves, M. M., Ribeiro, A. P., Matos, M., Santos, A., \& Mendes, I. (2010). The innovative moments coding system: A coding procedure for tracking changes in psychotherapy. In S. Salvatore, J. Valsiner, S. Strout, \& J. Clegg (Eds.), YIS: Yearbook of idiographic science 2009 (Vol. 2, pp. 107-130). Rome: Firera Publishing Group.

Gonçalves, M. M., Ribeiro, A. P., Mendes, I., Matos, M., \& Santos, A. (2011). Tracking novelties in psychotherapy process research: The innovative moments coding system. Psychotherapy Research, 21, 497509. doi:10.1080/10503307.2011.560207

Gonçalves, M. M., Ribeiro, A. P., Santos, A., Gonçalves, J., \& Conde, T. (2009). Manual for the return to the problem coding system*version 2. Unpublished manuscript, Department of Psychology, University of Minho, Braga, Portugal.

Gonçalves, M. M., Ribeiro, A. P., Stiles, W. B., Conde, T., Matos, M., Martins, C., \& Santos, A. (2011). The role of mutual in-feeding in maintaining problematic self- narratives: Exploring one path to therapeutic failure. Psychotherapy Research, 21, 27-40. doi:10.1080/ 10503307.2010.507789

Gonçalves, O. F., \& Machado, P. P. P. (1999). Narrative in psychotherapy: The emerging metaphor [Special issue]. Journal of Clinical Psychology, 55, 1175-1177. doi:10.1002/(SICI)1097-4679(199910)55:10<1175:: AID-JCLP1>3.0.CO;2-S

Hermans, H. J. M., \& Dimaggio, G. (2007). Self, identity, and globalization in times of uncertainty: A dialogical analysis. Review of General Psychology, 11, 31-61. doi:10.1037/1089-2680.11.1.31

Hermans, H., \& Kempen, H. (1993). The dialogical self. Meaning as movement. San Diego, CA: Academic Press.
Hill, C. A., Knox, S., Thompson, B. J., Nutt Williams, E., Hess, S. A., \& Ladany, N. (2005). Consensual qualitative research: An update. Journal of Counseling Psychology, 52, 196-205. doi:10.1037/0022-0167.52.2 .196

Hill, C. E., \& Lambert, M. J. (2004). Methodological issues in studying psychotherapy processes and outcomes. In M. J. Lambert (Ed.), Bergin and Garfield's Handbook of psychotherapy and behavior change (5th ed., pp. 84-135). New York: John Wiley \& Sons, Inc.

Holland, J., Currier, J., \& Neimeyer, R. A. (2006). Meaning reconstruction in the first two years of bereavement: The role of sense-making and benefit-finding. Omega: Journal of Death and Dying, 53, 175-191.

Holland, J. M., \& Neimeyer, R. A. (2010). An examination of stage theory of grief among individuals bereaved by natural and violent causes: A meaning-oriented contribution. Omega, 61, 103-120.

Jacobson, N. S., \& Truax, P. (1991). Clinical significance: A statistical approach to defining meaningful change in psychotherapy research. Journal of Consulting and Clinical Psychology, 59, 12-19. doi:10.1037/ 0022-006X.59.1.12

Keesee, N. J., Currier, J. M., \& Neimeyer, R. A. (2008). Predictors of grief following the death of one's child: The contribution of finding meaning. Journal of Clinical Psychology, 64, 1145-1163. doi:10.1002/jclp.20502

Lambert, M. J., Burlingame, G. M., Umphress, V., Hansen, N. B., Vermeersch, D. A., Clouse, G. C., \& Yancha, S. C. (1996). The reliability and validity of the Outcome Questionnaire. Clinical Psychology \& Psychotherapy, 3, 249-258. doi:10.1002/(SICI)1099-0879(199612)3: $4<249:$ :AID-CPP106>3.0.CO;2-S

Lichtenthal, W. G., \& Cruess, D. G. (2010). Effects of directed written disclosure on grief and distress symptoms among bereaved individuals. Death Studies, 34, 475-499. doi:10.1080/07481187.2010.483332

Lichtenthal, W. G., Cruess, D. G., \& Prigerson, H. G. (2004). A case for establishing complicated grief as a distinct mental disorder in the DSM-V. Clinical Psychology Review, 24, 637-662. doi:10.1016/j.cpr 2004.07.002

Lichtenthal, W. G., Currier, J. M., Neimeyer, R. A., \& Keesee, N. J. (2010). Sense and significance: A mixed methods examination of meaning-making following the loss of one's child. Journal of Clinical Psychology, 66, 791-812.

Machado, P. P., \& Fassnacht, D. (2012). The Outcome Questionnaire $(O Q-45)$ in a Portuguese population: Psychometric properties, norms and confirmatory factor analysis. Manuscript in preparation.

Machado, P. P. P., \& Klein, J. (2006). Outcome Questionraire-45: Portuguese psychometric data with a non-clinical sample. Poster presented a the 37th Annual Meeting of the Society for Psychotherapy Research, Edinburgh, Scotland.

Matos, M., Santos, A., Gonçalves, M. M., \& Martins, C. (2009). Innovative moments and change in narrative therapy. Psychotherapy Research, 19, 68-80. doi:10.1080/10503300802430657

McAdams, D. P. (1993). The stories we live by: Personal myths and the making of the self. New York: William Morrow.

McDevitt-Murphy, M. E., Neimeyer, R. A., Burke, L. A., \& Williams, J. L. (in press). Assessing the toll of traumatic loss: Psychological symptoms in African Americans bereaved by homicide. Psychological Trauma: Theory, Research, Practice, and Policy.

Mendes, I., Ribeiro, A. P., Angus, L. E., Greenberg, L. S., Sousa, I., \& Gonçalves, M. M. (2010). Narrative change in emotion-focused therapy: How is change constructed through the lens of the innovative moments coding system? Psychotherapy Research, 20, 692-701. doi: 10.1080/10503307.2010.514960

Neimeyer, R. A. (2001). Meaning reconstruction and the experience of loss. Washington, DC: American Psychological Association. doi: 10.1037/10397-000

Neimeyer, R. A. (2006a). Lessons of loss: A guide to coping. Memphis, TN: Center for the Study of Loss and Transition.

Neimeyer, R. A. (2006b). Re-storying loss: Fostering growth in the post- 
traumatic narrative. In L. Calhoun \& R. Tedeschi (Eds.), Handbook of posttraumatic growth: Research and practice (pp. 68-80). Mahwah, NJ: Lawrence Erlbaum.

Neimeyer, R. A. (2009). Constructivist psychotherapy. New York: Routledge.

Neimeyer, R. A., Baldwin, S., \& Gillies, J. (2006). Continuing bonds and reconstructing meaning: Mitigating complications in bereavement. Death Studies, 30, 715-738. doi:10.1080/07481180600848322

Neimeyer, R. A., Burke, L. A., Mackay, M. M., \& van Dyke-Stringer, J. G. (2010). Grief therapy and the reconstruction of meaning: From principles to practice. Journal of Contemporary Psychotherapy, 40, 73-83. doi:10.1007/s10879-009-9135-3

Neimeyer, R. A., \& Holland, J. M. (2006). Bereavement overload. In N. J. Salkind (Ed.), Encyclopedia of human development (pp. 49-72). Thousand Oaks, CA: Sage.

Polkinghorne, D. E. (2004). Narrative therapy and postmodernism. In L. E. Angus \& J. Mcleod (Eds.), The handbook of narrative psychotherapy: Practice, theory and research (pp. 53-67). London: Sage doi:10.4135/ 9781412973496.d5

Prigerson, H. G., Horowitz, M. J., Jacobs, S. C., Parkes, C. M., Aslan, M., Goodkin, K., . . . Maciejewski, P. K. (2009). Prolonged grief disorder: Psychometric validation of criteria proposed for DSM-V and ICD-11. PLoS Medicine, 6, 1-12.

Prigerson, H., \& Maciejewski, P. (2006). A call for sound empirical testing and evaluation of criteria for complicated grief proposed for the DSM-V. Omega: Journal of Death \& Dying, 52, 9-19.

Prigerson, H. G., Maciejewski, P. K., Reynolds, C. F., III, Bierhals, A. J., Newsom, J. T., Fasiczka, A., . . . Miller, M. (1995). Inventory of complicated grief: A scale to measure maladaptive symptoms of loss. Psychiatry Research, 59, 65-79. doi:10.1016/0165-1781(95)02757-2

Rando, T. A., (2012). Is It Okay For You To Be Okay? In R. A. Neimeyer (Ed.), Techniques of grief therapy: Creative practices for counseling the bereaved (pp. 149-151). New York: Routledge.

Ribeiro, A. P., Bento, T., Salgado, J., Stiles, W. B., \& Gonçalves, M. M. (2011). A dynamic look at narrative change in psychotherapy: A case study tracking innovative moments and protonarratives using state space grids. Psychotherapy Research, 21, 54-69. doi:10.1080/10503307.2010 .504241

Ribeiro, A., Cruz, G., Mendes, I., Angus, L., Greenberg, L., Sousa, I., . . . Gonçalves, M. (2012). Mutual in-feeding in client centered therapy for depression. Manuscript in preparation.

Ribeiro, A. P., \& Gonçalves, M. M. (2010). Innovation and stability within the dialogical self: The centrality of ambivalence. Culture \& Psychology, 16, 195-212. doi:10.1177/1354067X10361400

Ribeiro, A. P., \& Gonçalves, M. M. (2011). Maintenance and transformation of problematic self-narratives: A semiotic-dialogical approach. Integrative Psychological \& Behavioral Science, 45, 281-303. doi: 10.1007/s12124-010-9149-0

Ribeiro, A., Gonçalves, M. M., \& Bento, T., (2010). Manual for the protonarratives coding system. Unpublished manuscript, Department of Psychology, University of Minho, Braga, Portugal.

Ribeiro, A., Mendes, I., Angus, L., Greenberg, L., Sousa, I., Stiles, W. B., \& Gonçalves, M. (2012). Mutual in-feeding in emotion-focused therapy for depression. Manuscript in preparation.
Ribeiro, A., Ribeiro, E., Loura, J., Stiles, W. B., Sousa, I., Horvath, A. O., ... Gonçalves, M. M. (2012). Therapeutic collaboration and resistance: Describing the nature and quality of therapeutic relationship within ambivalence events using the therapeutic collaboration coding system. Manuscript in preparation.

Santos, A., Gonçalves, M. M., \& Matos, M. (2010). Innovative moments and poor outcome in narrative therapy. Counseling and Psychotherapy Research, 1, 1-11.

Santos, A., Gonçalves, M. M., Matos, M., \& Salvatore, S. (2009). Innovative moments and change pathways: A good outcome case of narrative therapy. Psychology and Psychotherapy: Theory, Research and Practice, 82, 449-466.

Sarbin, T. R. (1986). The narrative and the root metaphor for psychology. In T. R. Sarbin (Ed.), Narrative psychology: The storied nature of human conduct (pp. 3-21). New York: Praeger.

Seggar, L. B., Lambert, M. J., \& Hansen, N. B. (2002). Assessing clinical significance: Application to the Beck Depression Inventory. Behavior Therapy, 33, 253-269. doi:10.1016/S0005-7894(02)80028-4

Shear, K., Boelen, P., \& Neimeyer, R. A. (2011). Treating complicated grief: Converging approaches. In R. A. Neimeyer, D. Harris, H. Winokuer, \& G. Thornton, (Eds.) Grief and bereavement in contemporary society: Bridging research and practice (pp. 139-162). New York: Routledge.

Sousa, V., \& Rocha, J. C. (2011). Validação de metodologias de diferenciação clínica entre luto saudável e luto complicado. (Unpublished master's thesis). Instituto Superior de Ciências da Saúde do Norte Gandra, Portugal.

Steer, R. A., Brown, G. K., Beck, A. T., \& Sanderson, W. C. (2001). Mean Beck Depression Inventory-II scores by severity of major depressive episode. Psychological Reports, 88(3 Pt 2), 1075-1076. doi:10.2466/pr0 $.2001 .88 .3 c .1075$

Stroebe, M. S., Folkman, S., Hansson, R., \& Schut, H. (2006). The prediction of bereavement outcome: Developement of an integrative risk factor framework. Social Science \& Medicine, 63, 2440-2451. doi 10.1016/j.socscimed.2006.06.012

Stroebe, M., \& Schut, H. (1999). The dual process model of coping with bereavement: Rationale and description. Death Studies, 23, 197-224. doi:10.1080/074811899201046

Stroebe, M., Schut, H., \& Stroebe, W. (2007). Health outcomes of bereavement. The Lancet, 370, 1960-1973. doi:10.1016/S01406736(07)61816-9

Weertman, A., ArntZ, A., Dreessen, L., van Velzen, C., \& Vertommen, S. (2003). Short-interval test-retest interrater reliability of the Dutch version of the Structured Clinical interview for DSM-IV personality disorders (SCID-II). Journal of Personality Disorders, 17, 562-567. doi: 10.1521/pedi.17.6.562.25359

White, M., \& Epston, D. (1990). Narrative means to therapeutic ends. New York: Norton

Received May 23, 2012

Revision received October 2, 2012

Accepted October 18, 2012 